\begin{tabular}{|c|c|}
\hline Собственное трудоустройство & Личная и семейная ответственность \\
\hline Налаживание дела & Деловая ответственность \\
\hline Получение прибыли & Экономическая ответственность \\
\hline Формирование коллектива фирмь & Ответственность, как работодателя \\
\hline Создание новых товаров и услуг & Ответственность перед участниками рынка \\
\hline Польза обществу & Социальная ответственность \\
\hline
\end{tabular}

Таким образом, для успешного развития бизнеса в стране необходимо учитывать интересы и потребности предпринимателей и максимально увязывать их с интересами и потребностями общества. Не все предприниматели руководствуются в первую очередь финансовыми интересами. Их потребности разнообразны и зависят от стадии жизненного цикла бизнеса, а также ряда других факторов. Построена иерархия потребностей предпринимателей, которые по аналогии с потребностями имеют определенную последовательность в удовлетворении по мере развития бизнеса. Все потребности предпринимателя связаны с различными видами его ответственности.

$$
* * *
$$

1. Walker E. What Success Factors are Important to Small Business Owners? // International Small Business Journal. 2004. - 22(6). - pp. 577-594.

2. Бархатов В.И., Плетнев Д.А. Три измерения успешности малого и среднего бизнеса в России // Стратегическое планирование и развитие предприятий. Секция 1 // Материалы Шестнадцатого всероссийского симпозиума. Москва, 14-15 апреля 2015 г. Под ред. чл.-корр. РАН Г.Б. Клейнера / ЦЭМИ PAH - M., 2015. - C. 25-27.

3. Watson, K., Hogarth-Scott, S., \& Wilson, N. (1998). Small business start-ups: success factors and support implications. International Journal of Entrepreneurial Behavior \& Research, 4(3), 217-238.

4. Доброхлеб, В. Г. Демография: курс лекций : для специальности 080504.65 - Государственное и муниципальное управление / В. Г. Доброхлеб, С. А. Джавадова ; Федеральное агентство по образованию, Государственное образовательное учреждение высшего профессионального образования «Российский государственный гуманитарный университет», Институт экономики, управления и права, Экономический факультет, Кафедра экономических отношений. - Москва, 2012. - 247 с.

5. Плюхина А.А., Умнов В.А. Анализ зарубежного опыта государственной поддержки социального предпринимательства // Государственное управление. Электронный вестник Выпуск № 71. Декабрь 2018 г. [Электронный pecypc]. URL: http://e-journal.spa.msu.ru/vestnik/item/71_2018plukhina_umnov.htm (дата обращения: 29.09.2021).

6. Предпринимательский климат в России: Индекс опоры-2012. URL: https://opora.ru/upload/iblock/9b1/9b1e1d5309b279fec07c8dccc6b20372.pdf (дата обращения: 29.09.2021).

7. Бизнес в России: взгляд изнутри. URL: https://wciom.ru/analytical-reviews/analiticheskii-obzor/biznes-v-rossiivzglyad-iznutri (дата обращения: 29.09.2021).

\title{
Ярмухамметов И.Р. \\ Современные тенденции использования финансовых технологий в управлении активами инвесторов
}

ФГОБУВО Финансовый университет при Правительстве Российской Федераџии doi: 10.18411/trnio-10-2021-153

(Россия, Москва)

\section{Аннотация}

Предметом исследования в статье является рынок финансовых услуг. Объект исследования - финансовые технологии, которые используются в рамках управления активами инвесторов. В статье рассматриваются особенности использования финансовых технологий в управлении активами инвесторов на современном этапе, выполняется анализ статистических данных относительно изменения числа инвесторов на финансовом рынке, определяются современные тенденции в использовании финансовых технологий при управлении активами, а также выявляются направления совершенствования использования финансовых технологий с целью повышения их качества.

Ключевые слова: финансовые технологии, финансовые сервисы, управление 
активами, розничные инвесторы, управление капиталом инвесторов.

\section{Abstract}

The subject of research in the article is the financial services market. The object of the research is financial technologies that are used in the framework of investor asset management. The article examines the features of the use of financial technologies in the management of investors' assets at the present stage, analyzes statistical data on changes in the number of investors in the financial market, identifies current trends in the use of financial technologies in asset management, and also identifies areas for improving the use of financial technologies in order to increase them. quality.

Keywords: financial technologies, financial services, asset management, retail investors, investor capital management.

Управление активами инвесторов на современном этапе основано на использовании в качестве приоритета финансовых технологий, которые обеспечивают сокращение рисков при реализации финансовых операций и сокращение продолжительности их осуществления. Указанные преимущества ведут к росту числа их пользователей.

Стоит отметить активную деятельность инвесторов на современном этапе: по итогам исследования НАУФОР общая сумма, размещенная инвесторами на брокерских счетах и счетах доверительного управления, возросла почти в два раза: с 3.2 трлн руб. в 2019 году до 6 трлн руб. в 2020 году. Если рассматривать динамику объемов индивидуальных инвестиционных счетов, то данный показатель также возрос: с 220 млрд руб. в 2019 году до 375 млрд руб. в 2020 году. Подтверждающим фактом востребованности цифровых технологий на финансовом рынке является преобладание онлайн-каналов при открытии брокерских договоров в течение 2020 года - 72\% [3, с.3].

Одной из приоритетных причин повышения числа розничных инвесторов на финансовом рынке в 2020 году обуславливается сокращением доходности по депозитам. Согласно статистическим данным приток новых инвесторов на Московской бирже в 2020 году составил 5 млн чел., на Санкт-Петербургской бирже - 2,5 млн человек [4].

Другая не менее важная причина повышения числа розничных инвесторов на финансовом рынке - повышение качества инфраструктуры организаций, предоставляющих финансовые услуги, а именно финансовых технологий, которые обеспечивают взаимодействие с клиентом. Таким образом, реализация того или иного функционала становится более быстрой, а набор возможных опций возрастает, при этом необходимые финансовые манипуляций можно выполнить удаленно.

Стоит отметить, что современные условия финансового рынка характеризуются применением низких ставок, популяризацией торговли посредством приложений банков и брокеров, а также повышением защиты неквалифицированных инвесторов за счет реформы Банка России.

Финансовые технологии, используемые в настоящее время в сфере управления активами инвесторов, подразумевают под собой применение совокупности автоматизированных методов и средств анализа, в основе функционирования которых лежит использование цифровых систем. Важными последствиями использования финансовых технологий являются возможность обработки больших объемов информации в кратчайшие сроки, а также сокращение рисков допущения ошибок за счет исключения «человеческого фактора».

Если рассматривать аналитическое обзоры относительно актуальности рассматриваемой в статье темы, то необходимо обратиться к результатам аналитического исследования, реализованного компанией Accenture Consulting в 2020 году [1, с. 5].

Согласно полученным результатам исследования стратегических целей 120 банков выявлено, что девять из десяти глобальных финансовых организаций в качестве одного из приоритетов выделяют формирование клиентоориентированных экосистем на основе 
использования и совершенствования финансовых технологий. Для реализации указанного приоритета финансовые организации создают в рамках своей деятельности витрины, маркетплейсы и экосистемы, сформированные с учетом персонализации. Таким образом, инвестиционная составляющая становится доступной для граждан, а предложения финансовых организаций - адресными.

В настоящее время необходимо отметить следующие особенности использования финансовых технологий в управлении активами инвесторов:

- клиенториентированный подход финансовых организаций при создании продуктовой линейки финансовых услуг;

- необходимость разработки уникальных предложений по причине высокого уровня конкуренции в сфере предоставления финансовых услуг;

- необходимость совершенствования возможностей финансовых технологий по причине потребности клиентов в сервисах самообслуживания при управлении активами.

Указанные характеристики современного рынка финансовых услуг привели к трансформации данного вида бизнеса, в том числе и управления активами инвесторов наблюдается изменение форм предоставления услуг: из партнерских продуктов в экосистемы с единой структурой финансовых сервисов.

Таким образом, инвесторам предоставляется более широкий спектр возможных вариантов для вложения капитала, а также появляется возможность сравнения результативности вложений при выборе альтернативы.

Финансовые технологии, используемые в управлении капиталом инвесторов, подразумевают на современном этапе два подхода - нишевой и глобальный.

Первый из указанных связан с формированием финансовых услуг для клиентов, относящихся к конкретной сфере, а также совершенствование линейки с целью удовлетворения запросов именно данного сегмента клиентов.

Финансовые технологии, относящиеся к глобальному подходу, подразумевают предоставление совокупности финансовых услуг для большинства сфер жизни клиентов.

На современном этапе выявлены следующие тенденции в использовании финансовых технологий в рамках управления активами инвесторов:

1. Повышение востребованности финансовых технологий в рамках принятия управленческих решений (обработка больших массивов данных, использование критериев при дифференциации предложений услуг для клиентов, удалённая поддержка клиентов). Согласно исследованию компании $\mathrm{BDO}$, проведенному в 2020 году, 72\% респондентов подтверждают реализацию внедрения цифровых технологий в деятельности их финансовых организаций по направлению облачных вычислений, 56\% указали приоритет работы по направлению совершенствования аналитики с помощью финансовых технологий, $48 \%$ респондентов в приоритет ставят интеграцию Интернета вещей, 44\% респондентов развивают в первую очередь в компаниях искусственный интеллект, $33 \%$ респондентов подтвердили приоритетность совершенствования блокчейн в своей деятельности [2].

2. Повышение роли «regtech» в управлении активами на основе реализации проверки биографических данных, борьбы с отмыванием денег (AML) и реализации соблюдения законов об информационной безопасности и конфиденциальности. Согласно исследованию компании $\mathrm{BDO}, 48 \%$ респондентов, реализующих деятельность в сфере управления активами, указанное направление выделяют в качестве основы для создания уникальных инвестиционных продуктов [2]. 
3. Приоритетность конфиденциальности данных при управлении активами: современная ситуация на финансовом рынке в условиях пандемии COVID19 требует повышения внимания финансовых организаций по направлению разработки мер по предотвращению кибератак и защите персональных данных клиентов.

4. Несмотря на развитие финансовых технологий в рамках управления активами инвесторов в финансовых организациях, эффективность их деятельности будет зависеть от изменения общего проникновения на рынок финансовых услуг.

Таким образом, в результате исследования современных тенденций в области управления активами инвесторов на основе использования финансовых технологий, стоит отметить, что рассматриваемое направление развивается высокими темпами, но требует разработки мер по совершенствованию с целью повышения удовлетворенности клиентов и непрерывной конкуренции между финансовыми организациями.

Также требуется повышение финансовой грамотности розничных инвесторов, создание совокупности требований к прозрачности финансовых операций, а также разработка новых уникальных финансовых инструментов в целях поддержания конкуренции.

***

1. Accenture Consulting. Competing with banking ecosystems. - 2020. URL: https://www.accenture.com/_acnmedia/pdf-102/accenture-banking-ecosystem.pdf\#zoom=50 (дата обращения: 04.09.2021).

2. BDO. 5 финтех трендов в управлении активами. - 18.01.2021. URL: https://www.bdo.lv/ru-ru/ (дата обращения: 04.09.2021).

3. НАУФОР. Ежегодное исследование активности граждан на фондовом рынке. - 24.02.2021. URL: https://naufor.ru/tree.asp?n=21226 (дата обращения: 04.09.2021).

4. Эксперт PA. Финансовый сектор, Розничные инвестиции: от спринта к марафону. - 18.05.2021. URL: https://www.raexpert.ru/researches/ua/retail_investment_2021/\#part4 (дата обращения: 04.09.2021). 